\title{
Integrating SIS with the Cloud
}

\author{
Joaquim Campuzano ${ }^{1}$, José Luis Poy ${ }^{2}$ \\ 1Universitat Autònoma de Barcelona, Campus UAB 08193 Cerdanyola Barcelona \\ joaquim.campuzano@uab.cat \\ ${ }^{2}$ SIGMA Gestión Universitaria, Alcalde Barnils 64-68 08174 Sant Cugat Barcelona, \\ joan.lasierra@sigmaaie.org
}

Keywords

LMS, student performance, OLN, SIS, cloud.

\section{ABSTRACT}

Technology and Innovation are the backbone of the services and solutions provided by SIGMA, based on a highly open source development and deployment platform for J2EE5 certified application servers compliant on a multi-tier and high performance proven open architecture. Internationalization is one of SIGMA's top priorities, as well. For years SIGMA has established relationships with other European universities consortiums. Lately SIGMA has open new strategic areas of interest such as SaaS, BI, eLearning and Mobile. SIGMA focuses the development and support of two main suites of solutions VEGA Student Information System and ARGOS Research Information System.

"LMS paradigm, as it has evolved, falls short in three important ways:

1. the organization of learning experiences into discrete, artificially time-bound units,

2. the predominance of instructor-focused and content-centric tools in the CMS, and

3. the lack of persistent connections between learners, instructors, content, and the broader community across semesters and across class, program, and institutional boundaries."

We find the "open learning network" (or OLN) as an alternative to traditional LMS, (Mott \& Wiley 2009). With this approach in mind, SIGMA and UAB have started a project to lightly integrate VEGA Student Information System, FDPMS Final Degree Project Management System, WCMS Workcontract / Internship-contract Management System with the UAB LMS, Portfolio and internal and external MOOC experiences of UAB students.

\section{INTEGRATING SIS WITH THE CLOUD}

An LMS (Learning Management System) also called by same authors CMS (Course Management System), is defined by Wikipedia as:

"a software application for the administration, documentation, tracking, reporting and delivery of education courses or training programs.

LMSs range from systems for managing training and educational records to software for distributing online or blended/hybrid college courses over the Internet with features for online collaboration. Colleges and universities use LMSs to deliver online courses and augment on-campus courses. Corporate training departments use LMSs to deliver online training, as well as automate record-keeping and employee registration."

Surprisingly, or not, we cannot see in this definition a sentence like "LMS are used to improve student performance" or "are used by student to self-organize around learning topics" or "let students to contribute to learning process". LMSs, as the definition poses, are mainly used for the administration, documentation, tracking, reporting and delivery of courses or training programs. So, we must conclude that those are tools for people who need to manage courses or programs ... not for student - neither teachers sometimes - and not to improve learning neither teaching.

Bloom (1984) studied differences between the performance of group instruction and one-to-one tutoring. The author explained how the students instructed individually outperformed $98 \%$ of students instructed in a conventional classroom. That's what he called "the 2-Sigma Problem". 
The 2-Sigma problem challenge proposed by Bloom is trying to devise teaching-learning conditions that will enable the majority of students under group instruction to attain levels of achievement that can at present be reached only under good tutoring conditions.

Mott \& Wiley (2009) in their article "Open for Learning: The CMS and the Open Learning Network" published in the open-access journal "in education" explain how "instead of leveraging the Web to radically improve student performance and close Bloom's 2-Sigma gap, instructors and institutions are essentially making the old, content-centric paradigm more efficient, but leaving it largely unchallenged and unquestioned."

Wiley and Mott argue that CMS (or LMS) paradigm, as it has evolved, falls short in three important ways:

1. the organization of learning experiences into discrete, artificially time-bound units,

2. the predominance of instructor-focused and content-centric tools in the CMS, and

3. the lack of persistent connections between learners, instructors, content, and the broader community across semesters and across class, program, and institutional boundaries." (Mott \& Wiley 2009)

The authors propose the "open learning network" (or OLN) as an alternative to traditional LMS. Their proposal is a hybrid between the LMS and PLE (Personal Learning Environment), closing the false dichotomy between them. OLN approach considers that some key components should remain in core components of the institutional IT infrastructure and be private and secure - student information systems (SISs), identity and role repositories, proprietary content stores, secure online assessment applications, grade book and legal documentation - while other OLN components need not to be private - faculty and students blogs, wikis, portfolios, open courseware and open educational resource repositories, social features, etc. - and therefore can be spread across multiple applications in the cloud.

As dealing with separate systems, some mechanisms have to be provided to integrate information from Student Information Systems (oriented to academic management) and eLearning platforms (oriented to teaching). This integration, often carried out in a homemade way, gives a powerful set of people, information and resources to put them together and provide services to the community. This integration should be done, in our opinion, in accordance with the OLN model (see Figure 1, an Open Learning Network, by John Mott (2010)).

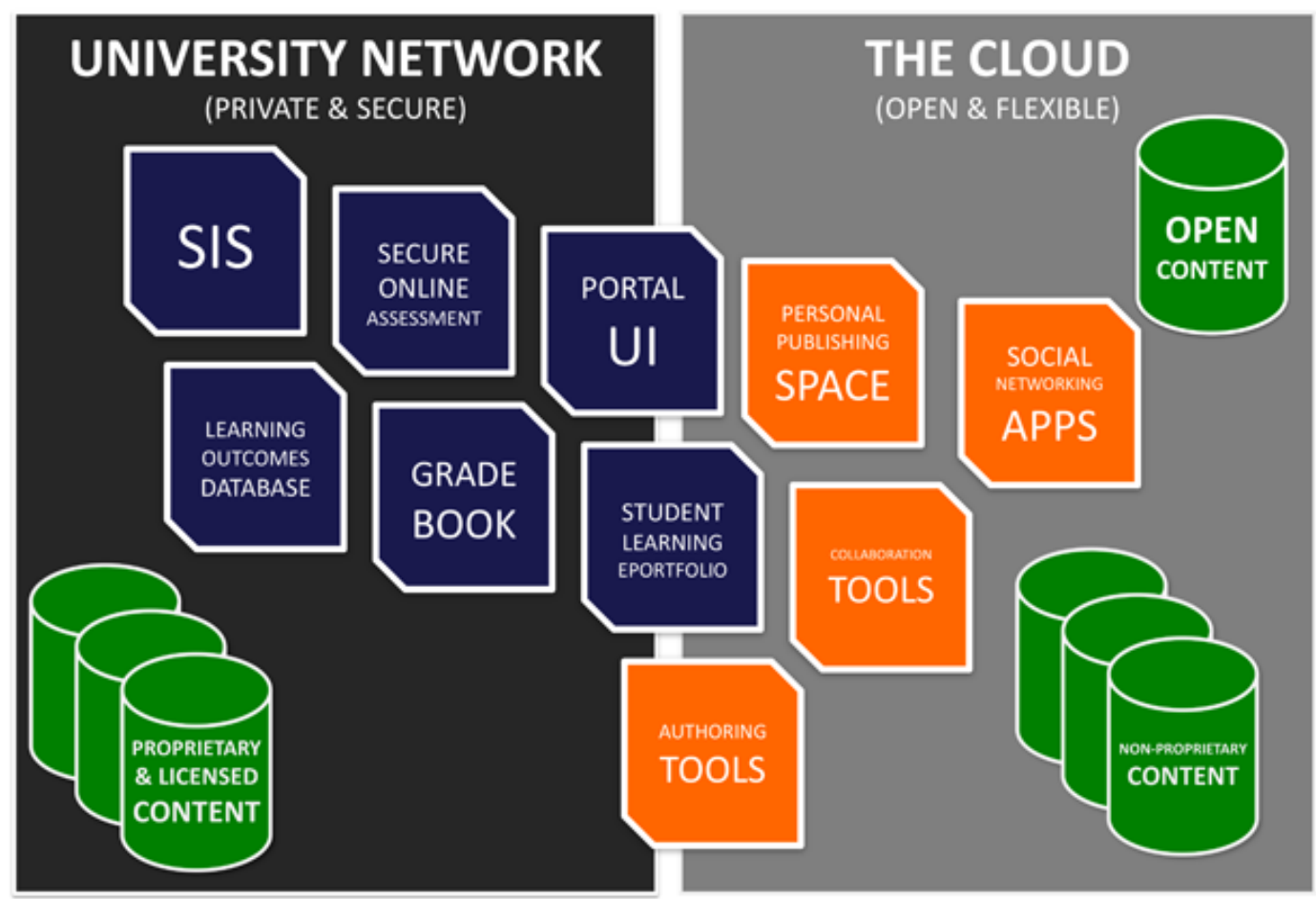

Figure 1. An Open Learning Network, by John Mott (2010) 
The OLN model implies changes to IT organization that must focus on maintaining the applications and data that are at the core of the institution's business and in providing integration mechanisms to use the best applications and tools - wherever they are.

These new roles, in SIGMA and UAB opinion, need to be implemented as a middleware infrastructure and, as can be seen in Figure 2 (Full featured OLN, by John Mott (2010)), based on data harvesting, single sign on, artifact exchange and evidence storage.

With this approach in mind, SIGMA and UAB have started a project to "lightly" integrate VEGA Student Information System, FDPMS Final Degree Project Management System, WCMS Workcontract / Internship-contract Management System with the UAB LMS, Portfolio and internal and external MOOC experiences of UAB students.

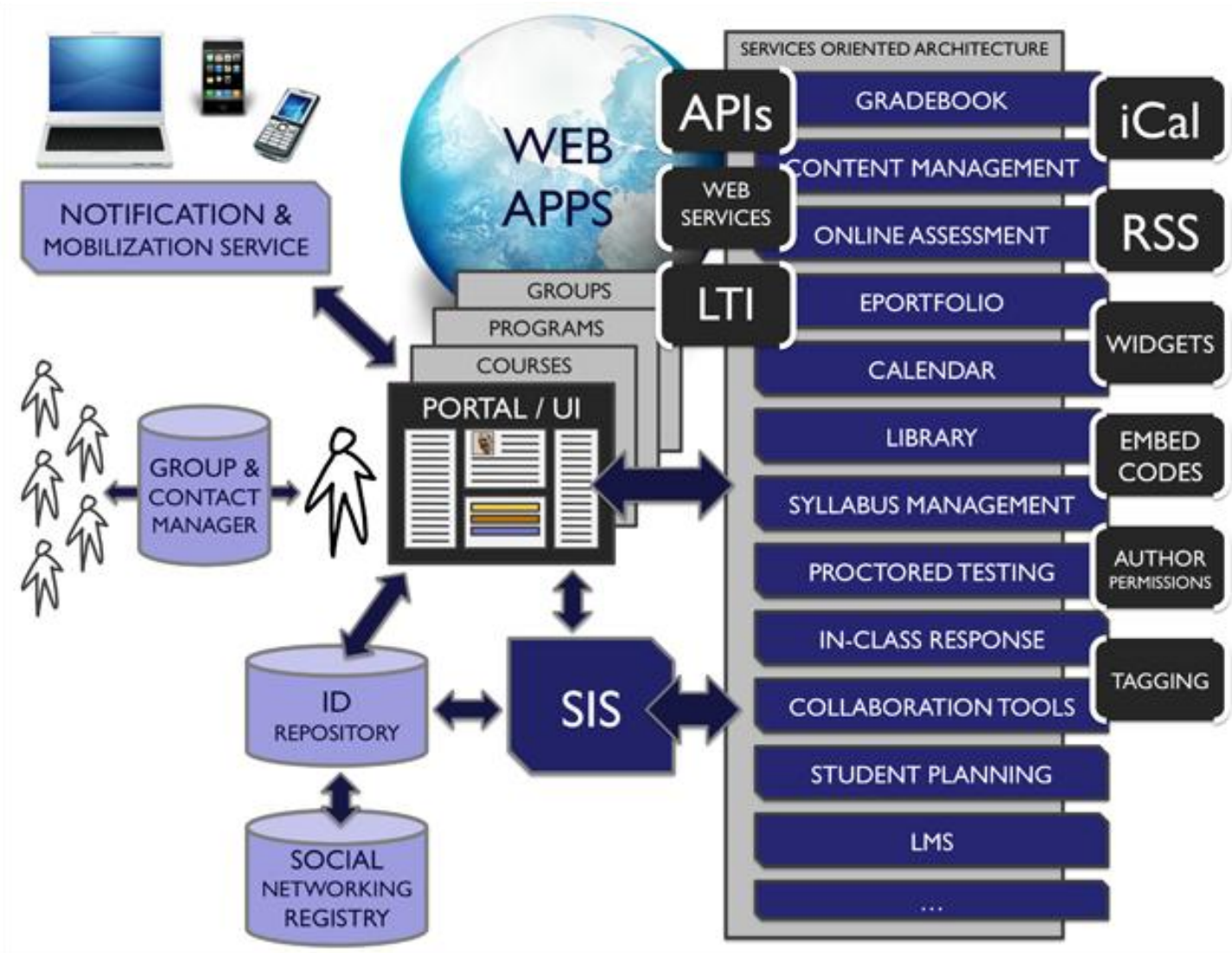

Figure 2. Full featured OLN, by John Mott (2010)

\section{REFERENCES}

Bloom, B. S. (1984). The 2-Sigma Problem: The Search for Methods of Group Instruction as Effective as One-to-One tutoring. Educational Researcher, 13(6), 4-16. http://dx.doi.org/10.3102/0013189X013006004

Mott, J. (2010). Envisioning the Post-LMS Era: The Open Learning Network. Educause Quartely, 33(1). Retrieved from: http://www.educause.edu/ero/article/envisioning-post-lms-era-open-learningnetwork

Mott, J. And Wiley, D. (2009) “Open Learning: The CMS and the Open Learning Network", In education (open-access journal), Technology \& Social Media (Special Issue, Part 1), December 2009, 15(2). Retrieved from: http://www.ineducation.ca/article/open-learning-cms-and-open-learningnetwork 


\section{AUTHORS}

Joaquim Campuzano, Director of Information System Planning Area, UAB

Master's Degree in Sociological Applied Research at Universitat Autònoma de Barcelona - UAB (intended 2013), ISO 20000 Consultant at EXIN (2011), ITIL Service Manager and ITIL expert certification at EXIN (2007-2010), Postgraduate in Information Systems Management at Universitat Politècnica de Catalunya (2001-2002), PhD courses in Images, Graphics and Artificial Intelligence at UAB (1990-1992), Computer and Software Engineer at UAB (1985-90).

He works for UAB since 1994, covering different technical and managerial roles. He has been the Elearning Office technical director (2009-2012), Service Delivery and Systems Unit director at UAB Computer Service Centre (2000-2009) and Information Systems teacher at UAB (2007-2011). As Information Systems Planning Director he manages a 100 people technical team with analysts and process planning experts, software engineers, programmers, multimedia, design and teaching support specialists. His main activity area includes planning, analyzing and ensuring the quality and coordination of processes related to Information and Communication Technologies (ICT) and the information systems, facilitating the execution of business processes to achieve the objectives established in the strategic planning at UAB.

Jose Luis Poy, CTO Chief Technology \& Innovation Officer

MBA at Universitat Politècnica de Catalunya (2005 - 2006),

Postgraduate in Information Systems Manager at Universitat Politècnica de Catalunya (2004 - 2005),

Postgraduate in Production Manager at Institut Català de Tecnologia (2003 - 2003),

Computer and Software Engineer at Universitat Autònoma de Barcelona (1985 - 1991).

He works for SIGMA since 1994, covering different technical and managerial roles. He has been the COO Chief Operations Officer for the SIGMA's 2008-2012 Transformation Plan, managing a 100 people Software Engineering team, with activity areas in Product, Service and Market Strategy, Annual Budget for incomes and costs, Organization, Quality and Methodology, Internationalization, Full Product Life Cycle (PreSales, Execution,PostSales (Project, Product, Service), Project and Resources Management, Software Factory, J2EE Platform, Out of The Box Implantation \& SaaS, Customer Service continuous improvement, Help Desk \& SLA). As CTO, his main current activity is related to innovation and technology, with special interest areas as Mobile Apps, BI platforms, eLearning platforms and Cloud services. He is a member of RS3G, group in which works to facilitate the European Student Mobility, and he is also a member of EuroCRIS, organization in which deals with Research Information Systems standards. 